\title{
Potential of environmental responsibility and financial potential of innovative mechanical engineering enterprises in Ukraine
}

\author{
Iuliia Gernego ${ }^{1, *}$, Liudmyla Petrenko ${ }^{2}$, and Mykhailo Dyba ${ }^{1}$ \\ ${ }^{1}$ Kyiv National Economic University named after V. Hetman, Corporate Finance and Controlling Department, 03057 Prospect Peremogy \\ 54/1, Kyiv Ukraine \\ ${ }^{2}$ Jagiellonian University, program in Intellectual Property and New Technologies that is jointly organized by the Jagiellonian University \\ of Krakow, the World Intellectual Property Organization and the Patent Office of the Republic of Poland, 31-007 ul. Gołębia 24, Cracow, \\ Poland
}

\begin{abstract}
In the era of sustainable economy, the environmental responsible companies provide an important background both for particular industry and national economy competitiveness. In particular, mechanical engineering plays an important role in the economy of Ukraine. In accordance with national statistic, the Ukrainian mechanical engineering provides $6.4 \%$ in total volume of industrial products and $\sim 4 \%$ of the gross value added in the GDP of Ukraine. At the same time, the global mechanical engineering industry environmental friendly activity is related to SDG 9 and SDG 12. In March 2020, the Cabinet of Ministers adopted its Programme, reaffirming the commitment to the SDGs and their importance for Ukrainian economy development. Thereby, research problem lays upon the financial potential of innovative mechanical engineering enterprises in Ukraine providing the background to increase the potential of their environmental responsibility. The paper aims to provide scientific support on mechanical engineering industry representatives that tend to be environmental friendly. The research methodology is based on Ukrainian mechanical engineering enterprises data (5 years and 337 industry representatives) processed by statistical analysis. The financial and environmental indicators are represented in results section on the basis for six groups of mechanical engineering enterprises' analysis, namely: big unstable - 16; big stable - 17; medium unstable - 44; medium stable - 26; small unstable - 188; small stable - 46. Thus, the environmental dimension is increasingly taken into account by Ukrainian innovative mechanical engineering enterprises to be competitive. Big and medium stable enterprises are organizationally oriented to be environmentally sustainable. The main disadvantage of big and medium unstable enterprises is lack of financial resources for achieving sustainable goals. Small enterprises are lack of general capacity to conduct environmental support policy, but they are the most flexible ones that provide advantages in environmental management. The study results can be used within industrial and business programs of environmental responsible activity and its financial support. In relation to other branches or countries, more extensive study is required.
\end{abstract}

\section{Introduction}

\subsection{Research question}

In the global economy, the 21 st century brought forth new social challenges along with the technical problems and their solutions. New technological advancements and communications tools make new innovative ideas available in a wide range of social and economic areas. However, the technological progress often causes the lack environmental and societal ethics within business structures.

Profitability is at the heart of our understanding of successful business. At the same time, determining the impacts of vast expansion of economic activity into the environmental decline is becoming important worldwide. The economic activity is consuming vast quantities of resources from the environment, simultaneously returning the vast quantities of waste products into the environment. However, in the new global economy, the issue of environmental friendly business has received considerable critical attention. It is rather important to pay attention both to the financial prosperity and environmental policy of the company. Despite economy and ecology are often pitted against each other in the "profitability versus environment" debate, the modern companies are taking care of financial prosperity and environmental influences.

Reduction of man-caused load on the environment with simultaneous preservation of production capacity can be realized through a comprehensive greening of production processes in all sectors of the economy. Greening of production depends on greening of its individual components, the most important of which are technological solutions.

\footnotetext{
* Corresponding author: iuliiagern@ukr.net
} 
Modern economic realities prove that mechanical engineering is one of the most important branches for national economy development, because it plays an important role in accelerating both scientific and technological progress. Mechanical engineering provides the means of production to other sectors of the national economy, contributing to the renewal and accumulation of capital. In addition, mechanical engineering is one of the leading industries, concerning product value, investment attractiveness and employment increase globally. However, serious environmental problems are caused by activity within mechanical engineering, including environmental pollution, soil erosion and deforestation and climate changes. Thereby, the concept of profitable and environmental friendly mechanical engineering industry is at the heart of sustainable development understanding.

Since 2015, world leaders at the United Nations agreed to the 17 Sustainable Development Goals (SDGs) covering the three main dimensions of sustainable development: economic, environmental and social [1]. In particular, sustainable manufacturing, including sustainability of mechanical engineering industry, is related to SDG 9 and SDG 12 [2].

In accordance with SDG 9 "Build resilient infrastructure, promote inclusive and sustainable industrialization and foster innovation", environmental investments are among key business themes within sustainable society development. By 2030, the SDG 9 contain the measure of targets, including the following ones: to promote inclusive and sustainable industrialization, and raise significantly industry's share of employment and GDP in line with national circumstances; to upgrade infrastructure and retrofit industries to make them sustainable, with increased resource use efficiency and greater adoption of clean and environmentally sound technologies and industrial processes, all countries taking action in accordance with their respective capabilities [3].

SDG 12 "Ensure sustainable consumption and production patterns" suggests that societies need to find just and equitable ways to meet individual needs and aspirations within the environmental limits of the planet. Sustainable practices in the production phase of products and services will not provide sufficient responses to meet science-based emissions reduction targets, natural resource constraints or the growing demand for basic needs such as food, water and sanitation, and access to energy. Furthermore, demand for materials will likely outpace efficiency gains in supply chains as well as overwhelm already stretched ecosystem services. Consumption patterns need to be made sustainable, particularly lifestyles in industrialized societies, and reduce their environmental footprint to allow for the regeneration of natural resources on which human life and biodiversity depend. By 2030, the primary targets of this SDG contain substantially reduce waste generation through prevention, reduction, recycling, and reuse; encourage companies, especially large and trans-national companies, to adopt sustainable practices and to integrate sustainability information into their reporting cycle [4].
Mechanical engineering is one among the leading industries in Europe and globally. For instance, the industry produces about $9.1 \%$ of all production in manufacturing industries in European Union. The mechanical engineering companies are characterized by a relatively high manufacturing depth. The share of mechanical engineering value added of total manufacturing is higher than that of production, reaching around $11.5 \%$ [5]. Thus, mechanical engineering has both rather high financial potential and potential of environmental responsibility. Thereby, it is important to pay attention to above-mentioned issues within theoretical researches and applied conclusions.

Although the scientists payed attention to questions of sustainability within mechanical engineering industry. However, there is a great diversity of interpretations and ideas associated with the concept of sustainable manufacturing, including the consideration of financial potential and potential of environmental responsibility [ 6 - 8].

In light of recent trends of sustainable manufacturing, it is more difficult to find studies that provide a comparative analysis of indicators of its financial and environmental capacity and potential for further development. Thus, the current study tends to highlight the tendencies of mechanical engineering in Ukraine, namely their financial capacity and potential of environmental responsibility. The genesis of this thesis can be traced back to the time the authors became interested in sustainable development of innovative mechanical engineering enterprises in Ukraine and abroad.

\subsection{Previous researches}

Several previous studies and international organizations reports have found that innovative mechanical engineering enterprises have a significant potential to support sustainable development worldwide, including boosting social growth and environmental protection [911].

More recently, some governments, non-governmental organizations (NGOs), companies and academics have defined the unsustainability of our development model as one of the main problems faced in our society $[2 ; 12]$. In particular, the connection between growth of industrialization activity, increase in natural resource consumption and pollution was analyzed by Robinson et al. [13]. At the same time, the essence and industrial nature of sustainable development are also concerned within analytical reports of international organizations. In particular, the significant milestones of sustainable development, including environmental component, are considered within the "Our Common Future" report by the United Nations [14]. The above-mentioned researches created the basis for further applied researches, including estimation of the 17 Sustainable Development Goals (SDGs) covering the three key dimensions of sustainable development: economic, environmental and social [1].

Due to the industrialization widespread, there is also a measure of researches on sustainable mechanical 
engineering issue. So far, however, there has been little discussion about the mechanical engineering activity influence on environment. A search of the literature revealed few studies which define the potential of environmental responsibility of entities. However, there are some detailed investigations and published researches on cluster concept, considering sustainable development of mechanical engineering. In particular, the "cluster concept", based on sustainable development, is determined within the researches of Ketels and Schmitz $[15,16]$. Bergman and Edward paid attention to economic, social and ecological components of industrial clusters development [17]. The macroeconomic patterns of industrial entities development are considered within Steiner and Hartmann researches [18].

The above-mentioned patterns consider the nature of the anthropogenic impact of the cluster on the environment and determine the potential of such impact widespread. To ensure main consideration of the industry patterns, the definition of the term "metallurgical industrial cluster" was mentioned.

However, there is still a rather little published researches on financial potential and potential of environmental responsibility of mechanical engineering enterprises. Thus, the chosen problem is of a significant scientific interest nowadays.

\subsection{The scientific problem}

The scientific problem of this article lays upon the potential of providing flexible environmental support policy by innovative mechanical engineering enterprises, providing the basis for sustainable industry development in Ukraine. The hypothesis of the paper has both theoretical and applied background, concerning the profitable industry impact on sustainable development process, including influence on environmental conditions, which aims to activate sustainable development strategies implementation by innovative mechanical engineering enterprises. The aim of the current study is to identify similarities and differences, discover the best sustainable practices and present the strengths and weaknesses of the different groups of mechanical engineering enterprises in Ukraine to develop both financial potential and potential of environmental responsibility, based on their statistic. The object of the research is sustainable development boost within different groups of innovative mechanical engineering enterprises in Ukraine. The subject is financial potential and potential of environmental responsibility of above-mentioned industrial entities, contributing the social and economic growth of national and global economies.

\subsection{The research methodology}

The research methodology is based on Ukrainian mechanical engineering enterprises' data processed by statistical analysis. Data on financial position and indicators of effectiveness were collected by authors directly from financial and non-financial statements. A time period of research is 6 years: $2014-2020$; the number of mechanical engineering enterprises: 337. During the analysis, the following data were studied: indicators of production and productivity, income and expenditures, profitability and profit margin, EVITDA, the indicators of business sustainability, environmental and energy efficiency, estimation on ecological management practices. The financial and environmental indicators are analyzed on the basis of six groups of mechanical engineering enterprises definition, namely:

Big unstable - 16 (big mechanical engineering enterprises with rather unstable trends and indicators of activity);

Big stable - 17 (big mechanical engineering enterprises with stable trends and indicators of activity);

Medium unstable - 44 (medium mechanical engineering enterprises with rather unstable trends and indicators of activity);

Medium stable -26 (medium mechanical engineering enterprises with stable trends and indicators of activity);

Small unstable - 188 (small mechanical engineering enterprises with rather unstable trends and indicators of activity);

Small stable - 46 (small mechanical engineering enterprises with stable trends and indicators of activity).

The scientific novelty of the methodology is as follows: in the study, both the financial indicators and indicators of environmental influence of different groups of innovative mechanical engineering enterprises are analyzed through compartment of their strengths and weaknesses. On the one hand, this provides opportunity to define the role of financial stability for enterprises' sustainability for each group representative. On the other hand, this allows to estimate the influence of concentration of efforts on sustainability into the risks of failure and financial results.

\subsection{The current research structure}

The current research consists of the following parts: primarily, the theoretical and applied framework based on financial indicators of Ukrainian mechanical engineering enterprises activity is provided; secondly, the sustainable development phenomenon is described; the current situation of Ukrainian mechanical engineering enterprises' efforts concentration on sustainable development, including environmental challenges, is represented; then, the research conclusions on environmental and financial potential of mechanical engineering enterprises in Ukraine are provided.

The research practical implication is that results can be used within national innovative environmental strategies to accept community challenges both on national and regional levels.

\section{Main theoretical and applied assumptions of the research}

\subsection{Concepts of innovative enterprises ecological management}

The concepts of ecological management provide a useful 
account of how the theoretical background for ecological potential development by innovative enterprises. The primary modern investigation on environmental responsible activity by profitable enterprises dates to the end of the XX century. At this time Nelson, Winter, Silverberg and other researchers formed an evolutionary economic theory, in which economic development was provided in the form of a non-uniform, impulsive process, most of which consisted of innovative and innovative changes affecting "natural" capital. The economic processes are considered as stable and depended on external factors [19]. The emphasis is made mainly on the periodic change of innovation within the abovementioned theories. At the same time, the attention is paid on the interdependence of economic processes and environmental phenomena.

The theoretical backgrounds on environmental problems and their financial solutions are considered within the following approaches (Figure 1):

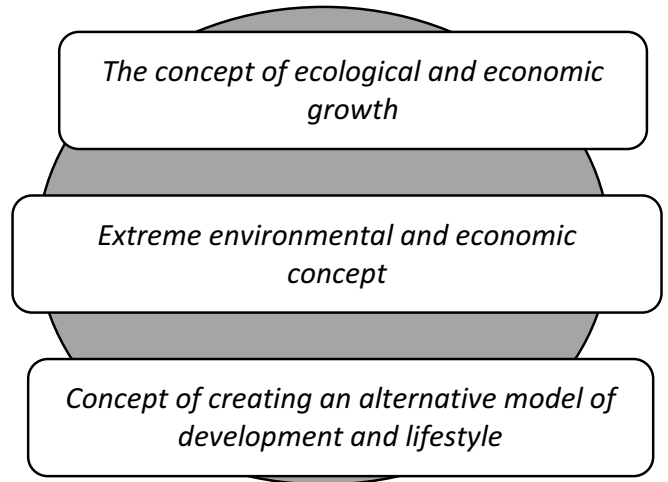

Fig. 1. The concepts on environmental growth.

The extreme environmental and economic concept represents concepts that are based on rather negative attitude to social and economic development on the basis of environmental component (Forrester, Meadows, Boulding, Michelle, Dame, Mansholt, Taylor, Puru). The concept of ecological and economic growth represents the system of sustainable development (Baroque, Jenks). The concept of creating an alternative model of development and lifestyle focuses on the social factors and environmental development (Reimers) [20-22].

The environmental concepts of a relatively stable dynamic system of equilibrium is based on the principle of systematic development. In accordance with abovementioned principle, the "ecosystem" concept as the combination of both inorganic and organic factors of economic and financial development is introduced by Tensley. The issues of systematic development and equilibrium are also considered within the concept of "environmental sustanability", which represents a qualitative and quantitative ratio of human-modified and natural environmental components and processes. At the same time, the definition of "ecosystem" becomes widespread within the business development concepts. According to Boyet, in order to succeed in business, the manager has to develop the "environmental awareness" along with managerial goals. The attention is also paid to "business ecosystem", which provide the environment for strategic business development. The definition of the concept of "environmental management system" was primarly defined in the UK Standard BS 7750 (Environmental Management Systems) in 1992 and described as part of a generalized management system, which includes planning processes, organizational structure, practical work, division of responsibilities, as well as resources and procedures for the development, implementation and evaluation of the obtained results (ISO 14001. Environmental management systems Specification with guidance for use).

The American Society of Mechanical Engineers (ASME) paid attention to the social (including, environmental) responsibility in mechanical engineering. The principles of force, energy and motion are being concern, mechanical engineers use their knowledge of design, manufacture, and operational processes to advance the world around us, improve safety, ability to manage economic with strength and responsibility throughout the world [23, 24].

The Mechanical Engineering Industry Association (VDMA) analytical researches provide evidence on the role of the mechanical engineering industry growth for sustainable development and growth within the European economy. In particular, the importance of investment into the inclusive growth and ecological development within mechanical engineering industry is considered by industrial experts in developed economies [25].

The environmental management in Ukraine is considered as a market-oriented (economic) mechanism for improving the environment at all levels of management and is contrasted to the administrativecommand mechanism of environmental regulation. This creates a number of "ambiguities" that make it impossible to perform the main task of environmental management, namely the introduction of an effective system of environmentally friendly management at the enterprise level.

\subsection{System for mechanical engineering entities environmentaly responsible development management}

Taking into account the targets of sustainable development of the enterprise, including reducing the burden on the environment, increasing environmental competitiveness, it is important to justify the mechanism of environmentaly responsible development management and financing (Figure 2).

The basic element of the proposed system is a chain of "environmentally responsible development goals processes of environmental and economic drivers' mobilization - financial and environmental results", which characterizes the internal existing and potential of the enterprise and the possibility of its implementation. The complex application of functional, systemic, parametric, target and process approach is based on certain principles of ecological and economic management. Achieving priority goals is possible by mobilizing resource-saving drivers and optimizing the ratio of growth rates of the final product and the cost of natural resources: increasing the resource-saving effect of 
the introduction of new technology; ensuring the integrated use of raw materials, the introduction of advanced technologies for its processing; gradual dematerialization of production.

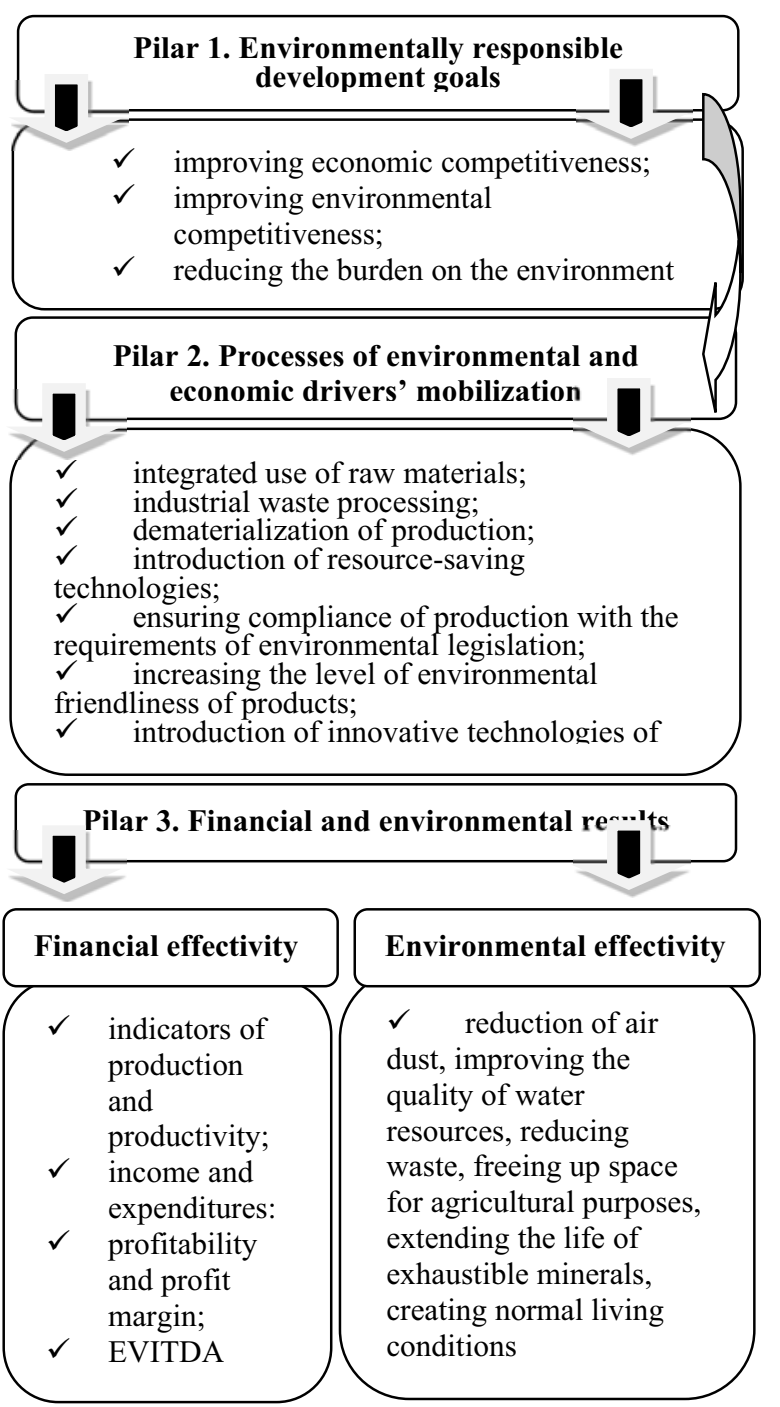

Fig. 2. Mechanism of environmentaly responsible development management: mechanical engineering case.

\section{Research results}

\subsection{Groups of mechanical engineering enterprises and indicators of their financial potential}

The potential of innovative development of mechanical engineering enterprises depends on the main economic characteristics that determine the features of their current activities and the prospects for their further development. The current research is based on the mechanical engineering enterprises classification in accordance with the criteria of their size and stability.

The primary indicators of financial potential are trends of changes in the average values of revenue from sales for each group of mechanical engineering enterprises (Figure 3).

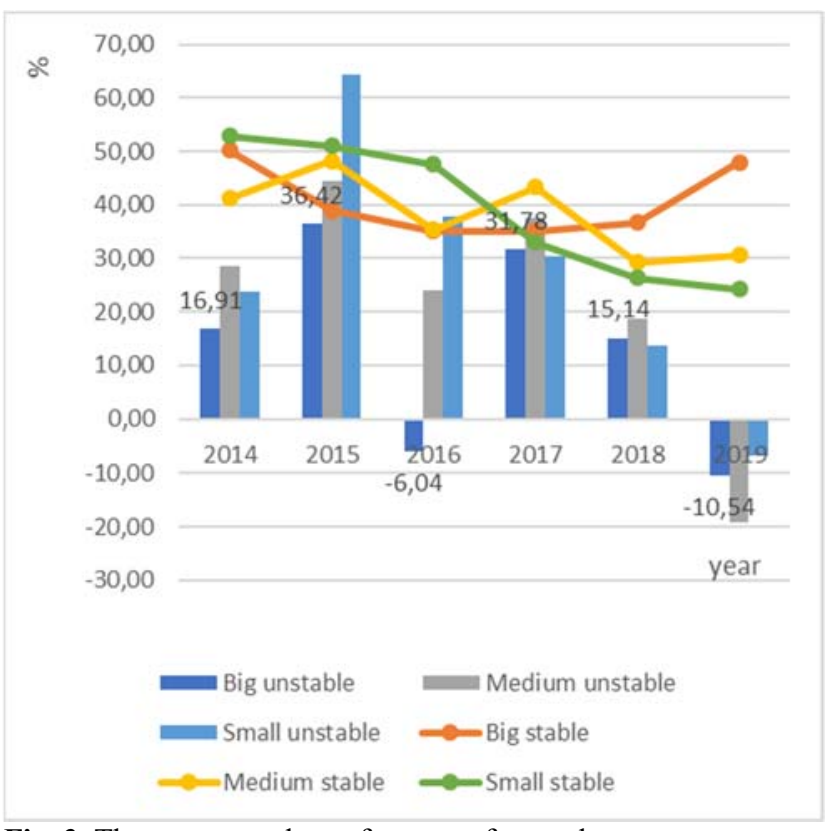

Fig. 3. The average values of revenue from sales.

The maximum growth rates are typical for 2015 and 2017. In 2019, we observe a slight decrease, which does not affect the overall upward trend during the study period. Such trends create the financial conditions for further implementation of innovation. However, the general tendency for unstable companies represents the maximum decrease in revenues in 2016 and 2019 years. Thereby, in accordance with the revenue indicator, currently the Ukrainian stable companies, independent of their size, have financial potential for environmental policy conduction.

At the same time, the tendencies to change the degree of depreciation of fixed assets are quite contradictory for Ukrainian mechanical engineering enterprises. It is possible to observe an increase in the degree of fixed assets deterioration over the last five years. The trend of the rate of outdated fixed assets increase is rather negative for further environmentaly responsible development and innovative growth. However, in this case there is a growing potential to replace these outdated fixed assets with innovative ones that will create the basis for innovative and environmentally responsible growth on a new technological basis.

The share of intangible assets in the total value of assets is insignificant, averaging from $0.3 \%$ to $0.5 \%$ during the chosen timeframe. These tendencies are available due to the peculiarities of the mechanical engineering industry. At the same time, this characterizes the contradictory basis for innovative development. However, the share of fixed assets in the total value of assets ranges on average from $25 \%$ to $35 \%$. This makes fixed assets the basis for future environmentally responsible and innovative growth on a scientific and technical basis.

Due to the above-mentioned contradictory tendencies of mechanical engineering enterprises in Ukraine, the trend of changes in revenue and asset value per employee becomes an important indicator of financial potential (Figure 4 and Figure 5). 


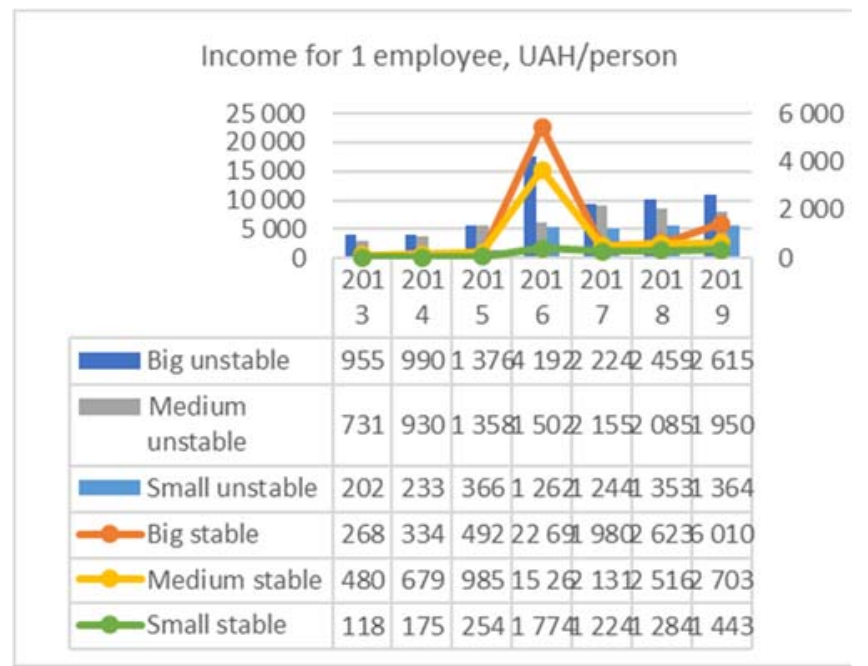

Fig. 4. The average values of revenue from sales per employee.

The compartment of data from different groups of representatives shows that the main increase of indicator is typical for stable big and medium enterprises. At the same time, instead of their stability, the small stable mechanical engineering enterprises have rather low indicators of revenue per one employee. Thus, they are the weakest ones for achieving environmentally responsible development goals in the group of stable enterprises in accordance with revenue indicator.

The second important indicator is the average asset value per employee (Figure 5).

Assets value for 1 employee, UAH/person

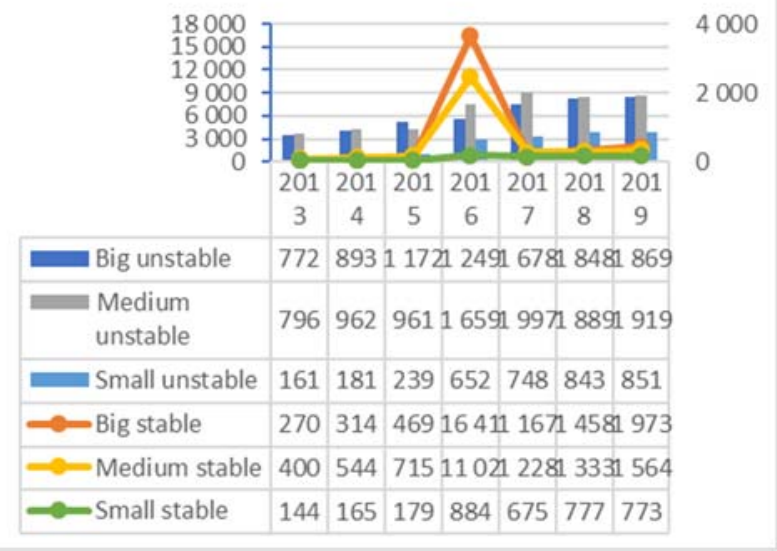

Fig. 5. The average assets values per employee.

The tendency of average assets values per employee is the same as the above-mentioned tendency of revenue changes. Thus, the enterprises that represent the group of big and medium mechanical engineering enterprises have the most appropriate basis for innovative activity implementation and environmentally responsible goals achievement.

One more important indicator of financial potential is the value added indicator that represent the key to assessing the effectiveness of existing innovative solutions and technologies (Figure 6).

The maximum value added indicators are appropriate for big stable enterprises. The medium stable enterprises represent the growing tendencies of increase. Both the small stable and small unstable enterprises have the weakest positions in accordance with value added indicator.

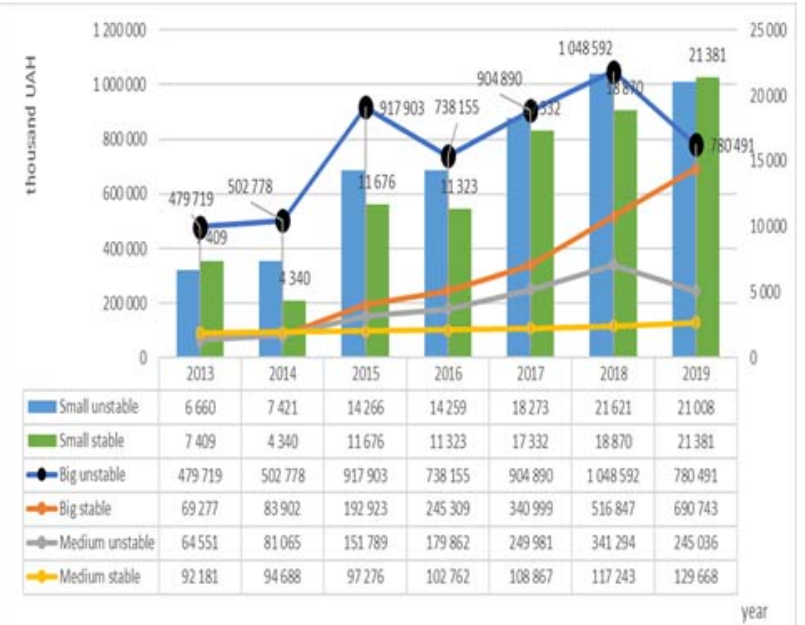

Fig. 6. The value added indicator.

At the same time, the value added trends are not always comparable to EBIDTA and EBIDTA profitability (Figure 7).

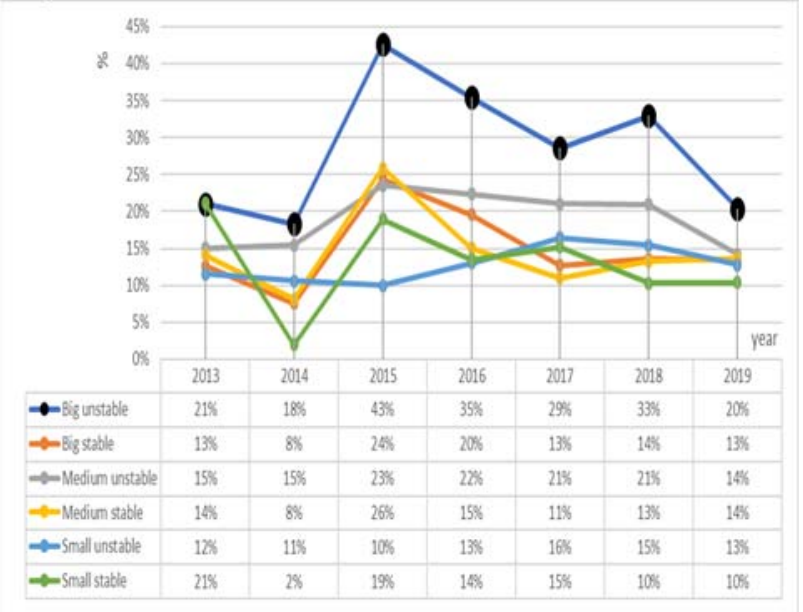

Fig. 7. The changes of indicators of EBIDTA profitability

The indicators of EBIDTA profitability have the increase tendency for all groups of mechanical engineering enterprises. This shows the available financial for further environmentally responsible development of industry in Ukraine. At the same time, the represented indicators of financial potential show that the groups of big and medium stable enterprises have the highest potential for further environmentally responsible development.

\subsection{Indicators of Ukrainian mechanical engineering enterprises' potential of environmental responsibility}

The potential of environmental responsibility of mechanical engineering enterprises in Ukraine is estimated, based on evaluation of social responsibility strategies and their effectiveness in mitigating environmental impacts. 
The research is conducted for each group of mechanical engineering enterprises, namely big stable, big unstable, medium stable, medium unstable, small stable and small unstable. The research methodology is based on the following set of indicators:

- the level of environmental friendliness of production;

- a quantitative indicator of the $i$-th type of contamination of environmental components due to production;

- a specific indicator of economic losses caused by the unit of the $i$-th type of pollution;

- a quantitative indicator of the $j$-th type of ecodestructive influence on landscapes;

- specific indicator of economic losses caused by the unit of the $j$-th type of eco-destructive impact on landscapes;

- a quantitative indicator of the $z$-th ecodestructive effect directly on the human body:

- a specific indicator of economic losses caused by a single indicator of the $z$-th ecodestructive impact on the human body;

- a quantitative indicator of irrational extraction of minerals from the extracted rock mass;

- specific indicator of economic losses caused by irrational use of minerals;

- a quantitative indicator of the $g$-th type of environmental impact on biological objects;

- specific indicator of economic losses caused by this type of eco-destruction;

- the volume of production that caused the processes of eco-destruction.

Currently, only the primary three components of losses can be fully estimated. Thereby, the current research is based on analytical estimation of environmental friendliness level of production, estimating the social and environmental expenses of mechanical engineering enterprises (Figure 8).

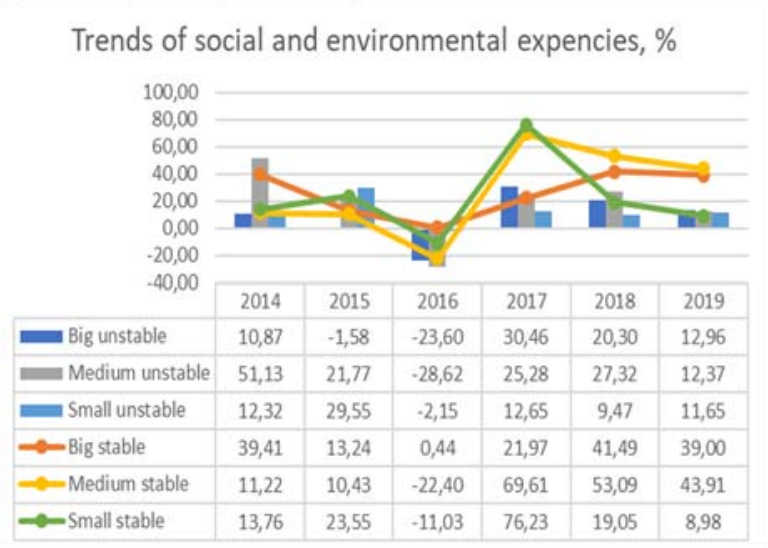

Fig. 8. The social and environmental expenses changes of mechanical engineering enterprises.

The above-mentioned data represent the tendency of mechanical engineering enterprises' expenses on achieving social and environmental goals. Thus, the most stable growth is represented by big stable enterprises. However, the worthiest timeframe in the context of environmental support was 2016 year. Simultaneously, the worthiest financial potential of mechanical engineering enterprises was also in 2016. Thus, there is dependence between financial potential of mechanical engineering enterprises and potential of their environmental responsibility.

\subsection{Ukrainian mechanical engineering enterprises' straights and weaknesses (SWOT analysis)}

In accordance with this new trend of promoting environmental friendly remanufacturing and social responsible business, it is essential to tackle the design of strategies and new technological developments to advance the mechanical engineering enterprises' innovativeness. It is clear that all of this is going to have a great impact on how the national mechanical engineering industry will be involved within national and global innovative process. The increasing attention should be paid to the strengths and weaknesses, represented for each group of enterprises, dependent on their financial potential and potential of environmental responsibility.

These strengths and weakness are analyzed in accordance with SWOT-analysis (sustainability SWOT - sSWOT) within the context of financial potential and potential of environmental responsibility. This will assist within driving action and collaboration on environmental challenges creating real business risks and opportunities. Moreover, this may motivate entrepreneurs for sustainable activity, particularly those with limited knowledge of environmental issues or corporate sustainability.

In accordance with previous research, big and medium stable mechanical engineering enterprises are the most environmentally sustainable. However, there are also some weaknesses along with strengths (Figure 9).

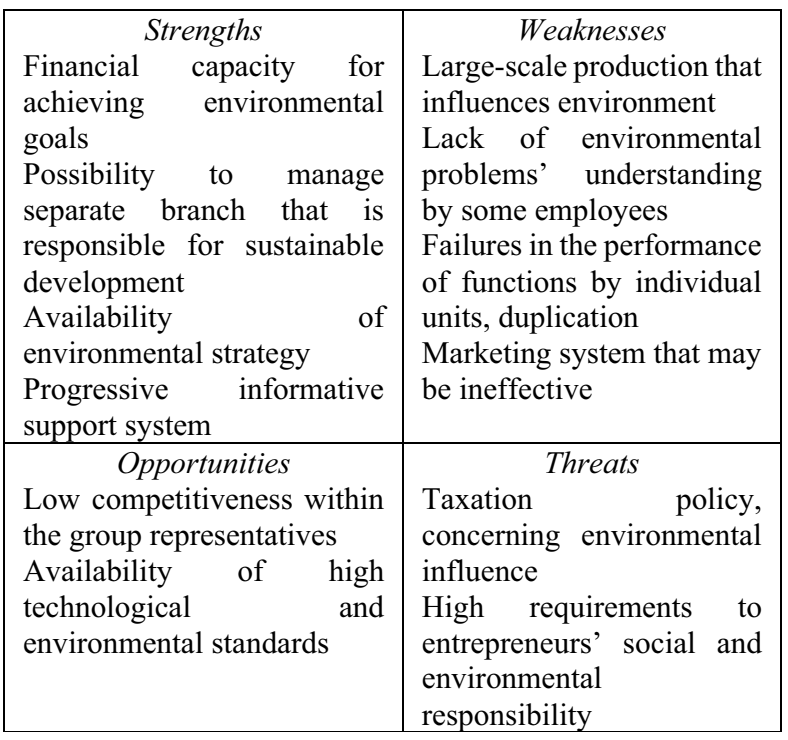

Fig. 8. Sustainability SWOT for big and medium stable enterprises.

Big and medium unstable enterprises are also rather important environmental friendly players. However, their instability creates some problems, concerning lack of financial resources for environment protection (Figure 9). 


\begin{tabular}{|c|c|}
\hline & \\
\hline $\begin{array}{l}\text { Rather strong market } \\
\text { position } \\
\text { Highly qualified staff that } \\
\text { concern environmental } \\
\text { sustainability as one of } \\
\text { competitive advantages } \\
\text { Organizational culture and } \\
\text { image that makes the basis } \\
\text { for further sustainable } \\
\text { activity }\end{array}$ & $\begin{array}{l}\text { Outdated equipment in } \\
\text { some areas } \\
\text { Lack of financial resources } \\
\text { for environment protection } \\
\text { during the instable } \\
\text { timeframes }\end{array}$ \\
\hline Opportunities & Threats \\
\hline $\begin{array}{l}\text { Availability of high } \\
\text { technological and } \\
\text { environmental standards } \\
\text { Barriers for potential } \\
\text { competition to entry the } \\
\text { segment }\end{array}$ & $\begin{array}{l}\text { Instability of social and } \\
\text { economic development } \\
\text { within global and national } \\
\text { economy } \\
\text { Demand instability }\end{array}$ \\
\hline
\end{tabular}

Fig. 9. Sustainability SWOT for big and medium unstable enterprises.

Both stable and unstable small enterprises are rather flexible in their decisions on environment protection. However, these enterprises have insufficient financial capacity to boost progressive initiatives on environment protection and sustainable development support (Figure 10).

\begin{tabular}{|c|c|}
\hline \begin{tabular}{l}
\multicolumn{1}{c}{ Strengths } \\
Flexibility in environmental \\
management \\
Flexibility in environmental \\
strategies building
\end{tabular} & \begin{tabular}{l}
\multicolumn{1}{c}{ Weaknesses } \\
Lack of product range \\
Insufficient range of \\
innovative technologies \\
implementation \\
Lack of financial resources \\
for environment protection
\end{tabular} \\
\hline $\begin{array}{l}\text { Opportunities } \\
\text { Upward trends in the target } \\
\text { market } \\
\text { Demand on innovative ideas } \\
\text { both at national and global } \\
\text { markets }\end{array}$ & \begin{tabular}{l}
\multicolumn{1}{c}{ Threats } \\
High-quality substitutes \\
High competitiveness, \\
concerning price policy
\end{tabular} \\
\hline
\end{tabular}

Fig. 10. Sustainability SWOT for small enterprises.

Thus, the environmental dimension is increasingly taken into account by Ukrainian innovative mechanical engineering enterprises to stay competitive. However, primarily big and medium stable enterprises are organizationally oriented to be environmentally sustainable. The main disadvantage of big and medium unstable enterprises is lack of financial resources for achieving sustainable goals. Small enterprises are lack of general capacity to conduct environmental support policy. At the same time, small enterprises are the most flexible that provide advantages in environmental management.

\section{Conclusions}

Given all that has been mentioned so far, one may state that environmental potential is getting growing importance within sustainable society. The primary analytical research of Ukrainian statistics shows the increasing deepening of mechanical engineering enterprises' environmental responsibility from their financial capacity.
There is an urgent need to concentrate more efforts on the potential of environmental responsibility of all groups of mechanical engineering enterprises in Ukraine. In accordance with the research sample, the mechanical engineering industry in Ukraine has the following structure:

- big stable enterprises make about $5 \%$, but this group representative have both financial capacity and experience in achieving environmental goals;

- around $18 \%$ of Ukrainian mechanical engineering enterprises may be concerned as big or medium, but unstable. Their environmental responsibility is particularly influenced by such instability, creating the barriers for sustainable development;

$-8 \%$ of medium stable enterprises also have enough financial capacity to be environmentally friendly and growing rapidly;

- the main part of mechanical engineering enterprises is small, namely $13 \%$ of them are concerned as stable and $55 \%$ of them are unstable. However, these enterprises produce the smallest share of production. They are rather flexible to be innovative, but have the lowest financial potential to support environmental friendly activity.

The study results of the current research can be used by their top-managers and spatialized branches that provides organizational and financial support for innovative projects in part of environmental protection.

In particular, the Ukrainian mechanical engineering industry stakeholders tend to pay attention on the following activities:

- stimulating the development of environmental management system within mechanical engineering enterprises;

- ability of top-managers to gather a network of enthusiastic stakeholders, who will assist at the initial stage of environmental support campaign, despite the lack of financial resources;

- ability of project managers to provide an environmental friendly business plan and its clear explanation for future stakeholders;

- creation of a centralized national system of informing the national business entities and investors regarding the need and advantages of environmental support;

- ability to provide an effective system for environmental stakeholders' stimulation at the national level;

- intensification of cooperation between public and private sector, concerning the strength of environmental support policy.

The essence of environmental responsibility potential is both applied and theoretical question. Thereby, there is a need for further research, considering environmental responsible model's practical implication within mechanical engineering enterprises activity. In particular, in relation to other countries, these studies should be applied with caution due to the national economies peculiarities. More extensive study is required. Thereby, this is the subject for future researches. 


\section{References}

1. Division for Sustainable Development Goals. Sustainable Development Knowledge Platform. (United Nations, Department of Economic and Social Affairs, 2020), https://sustainabledevelopment.un.org/ Accessed 14 Dec 2020

2. A. Sartal, R. Bellas, A. Mejias, A. Garcia-Collado, The sustainable manufacturing concept, evolution and opportunities within Industry 4.0: A literature review. Advances in Mechanical Engineering, 12(5) (2020)

3. SDG 9: Build resilient infrastructure, promote inclusive and sustainable industrialization and foster innovation. (SDG Compass, 2020), https://sdgcompass.org/sdgs/sdg-9/ Accessed 14 Dec 2020

4. SDG 12: Ensure sustainable consumption and production patterns. (SDG Compass, 2020), https://sdgcompass.org/sdgs/sdg-12/ Accessed 14 Dec 2020

5. H. Vieweg, An introduction to Mechanical Engineering: Study on the Competitiveness of the EU Mechanical Engineering Industry. (Munich: Ecorys, 2012)

6. A. Moldavska, T. Welo, The concept of sustainable manufacturing and its definitions: a content-analysis based literature review. Journal of Clean Production, 166 (2017)

7. K. Haapala, F. Zhao, J. Camelio, et al. A review of engineering research in sustainable manufacturing. Journal of Manufacturing Science and Engeneering, 135(4) (2013)

8. H. Millar, S. Russell, The adoption of sustainable manufacturing practices in the Caribbean. Business Strategy Environment, 20(8) (2011).

9. M. Petrushenko, H. Shevchenko, Management of ecological-economical conflicts within the framework of the theory of optimal mechanisms for resource distribution. Actual Problems of Economics, 141 (2013)

10. E. Aslaksen, The Relationship Between Engineers and Society: is it currently fulfilling its potential?. Journal and Proceedings of the Royal Society of New South Wales, 148 (2015)

11. M. Abu-Goukh, G. Ibraheem, H. Goukh, Engineering education for sustainability and economic growth in developing countries (the Sudanese Case). ProcediaSocial and Behavioral Sciences, 102 (2013)

12. Wilson C. Designing the purposeful world: the sustainable development goals as a blueprint for humanity. (New York: Routledge, 2018).

13. Robinson WC, Meadows DH, Meadows DL, et al. The limits to growth: a report for the Club of Rome's project on the predicament of mankind. Demography, 10(2) (1973).
14. World Commission on Environment Development. Report of the World Commission on Environment and Development: Our Common Future. Part I. Common Concerns: 2. Towards Sustainable Development. Part II. Common Challenges: 4. Population and Human Resources. (Oslo: United Nations, 1987).

15. Ketels C. The Development of the cluster conceptpresent experiences and further developments. Sociology, 5 (2003).

16. Schmitz H. On the clustering of small firms. IDS bulletin, 23(3) (1992).

17. E. Bergman, J. Edward, Industrial and regional clusters: concepts and comparative applications. 2nd edition. (Regional Research Institute: Web Book of Regional Science, 2020).

18. M. Steiner, C. Hartmann, Looking for the invisible: material and immaterial dimensions of clusters. Presented at the Regional Studies Association Annual Conference on Regionalising the Knowledge Economy, (London, United Kingdom, 2001).

19. L. Hryniv, Environmentally balanced economy: problems of theory, (Lviv: LNU im. I. Franka, 2001).

20. V. Kravtsiv, Modern scientific approaches to the environment and socio-economic development. Environmental Economics, (Kyiv: Naukova dumka, 1998).

21. Iu. Gernego, L. Petrenko, M. Dyba, V. Tsarov. Innovative financing of creative projects on the Kickstarter platform: Ukrainian and Polish experience. E3S Web of Conferences, 166 (13019) (2020).

22. P. Maciaszczyk, M. Dyba, Iu. Gernego, Strategies of Human Development in the Context of Global Digital Change, Economic Studies journal, Bulgarian Academy of Sciences - Economic Research Institute, 5 (2019).

23. What is a Mechanical Engineer? (ASME, 2018), https://www.asme.org/career-education/k-12students/what-is-a-mechanicalengineer Accessed 14 June 2020

24. I.P. Okokpujie, O. S. I. Fayomi, S. O. Oyedepo, The Role of Mechanical Engineers in Achieving Sustainable Development Goals. Procedia Manufacturing, 35 (2019), 782-788

25. Raibagi K. Europe's mechanical engineering industry is set to bounce back next year. (VOXEUROP, 2020), https://www.europeandatajournalism.eu/eng/News/ Data-news/Europe-s-mechanical-engineeringindustry-is-set-to-bounce-back-next-year Accessed 14 Dec 2020 